\title{
Su casa es mi casa. Conversación con Antonio García Ángel
}

\author{
Su Casa es Mi Casa. A Conversation with Antonio Garcia Angel \\ Sua casa é minha casa. Conversa com Antonio García Ángela
}

\section{Ofelia Ros}

Ofelia Ros es investigadora del Instituto Caro y Cuervo de Colombia y profesora del Seminario Andrés Bello del mismo Instituto. Ha publicado varios artículos en revistas especializadas de las letras hispanas y la cultura latinoamericana. Entre ellos: “ ¿Cuándo acabará esta payasada?' El humor como zancadilla a la posición del amo en la literatura de César Aira" (RCLL, Revista de crítica literaria latinoamericana XXXVII/74, 2011), "La violencia de Buenos Aires a través del humor de Osvaldo Lamborghini en La causa justa" (Revista Canadiense de Estudios Hispánicos 37/3, 2013), "Conflicto social, humor y lenguaje en la literatura y el proyecto editorial de Washington Cucurto" (Latin American Research Review (LARR) 50/2, 2015). Asimismo el libro titulado Lo siniestro se sigue riendo en la literatura argentina de fines de siglo veinte se publicará a mediados del 2015 con el Instituto Internacional de Literatura Iberoamericana (IILI), Universidad de Pittsburgh. Correo electrónico: ofeliar@umich.edu

Entrevista

Documento accesible en línea desde la siguiente dirección: http://revistas.javeriana.edu.co doi: $10.11144 /$ Javeriana.cl19-38.scmc

\section{Cómo citar esta entrevista:}

Ros, Ofelia. "Su casa es mi casa. Conversación con Antonio García Ángel". Cuadernos de Literatura 19.38 (2015): 485-496. http://dx.doi.org/10.11144/Javeriana.cl19-38.scmc 
Antonio García Ángel nació en 1972 en la ciudad de Cali, Colombia. Es escritor y profesor de teoría literaria en la Pontificia Universidad Javeriana de Bogotá y columnista de la revista SoHo. Ha publicado las novelas Su casa es mi casa (Planeta, 2000), Recursos Humanos (Planeta, 2006) y Animales domésticos (Grupo Editorial Norma, 2010). Ha editado Las aventuras de Pinocho: historia de una marioneta (IDARTES 2010, Libro al viento); y realiza la selección, prologa y escribe la presentación de varios libros de la colección de IDARTES Libro al viento. Ha escrito los artículos: "Cruce de palabras desde las cruces: para llegar a cristo" (Cambio 16, 2002), "Vargas Llosa y el escribidor: literatura" (Cambio 16, 2004) y "Un plus para corredores" (Gatopardo, 2004). Ha ganado la distinción del Programa de Maestros y Discípulos de la firma relojera Rolex 2004 (The Rolex Mentor and Protégé Arts Initiative) y en el 2007 fue escogido como uno de los 39 escritores, menores de 39 años más representativos de América Latina, en el marco de Bogotá Capital Mundial del Libro. Esta entrevista contó con la colaboración de Liliana Matturro.

Ofelia Ros: ¿Cuáles fueron las influencias o los gustos literarios presentes en la escritura de Su casa es mi casa?

Antonio García Ángel: A ver, yo tengo insumos que son de siempre digamos, unas influencias que están en mi prosa y en mi forma de hacer historias, que siempre están ahí y otros que siento que complementan. Para la novela, yo estaba tratando de rendirle tributo al género policial porque había leído sistemáticamente y durante varios años novela policial y me había enamorado de la novela de Raymond Chandler.

Con el tiempo se han venido combinando otras influencias y se han mezclado, pero yo creo que en esa época, cuando estaba escribiendo la novela, tenía una influencia fuerte de Raymond Chandler. Sin embargo, estaba explorando como hacer una narrativa policial latinoamericana y sentía que esa era una referencia que no me alcanzaba, es decir, si tomaba las lecturas de la novela negra clásica, esos tipos que toman Bourbon, que usan gabardinas largas y sombrero y que se montan en un Packard, ese tipo como de noir, la única clave con la que lo podría seguir era la paródica. Pero para trabajar ese género acá en Colombia, y en Latinoamérica en general, es necesario hacer una adaptación. Entonces, me acuerdo que había leído muchísimo a un escritor que en ese momento me dio ciertas claves, el escritor mexicano Paco Ignacio Taibo. Él tiene un personaje que se llama Héctor Belascoarán Shayne, un detective privado mexicano que encarna aspectos populares de la cultura, elementos populares que me parecía debían tener mi novela. Y claro, también había leído a Manuel Vázquez Montalbán, que tiene a ese personaje que se llama Pepe Carvalho y había leído esa adaptación 
catalana barcelonesa como la de Mempo Giardinelli en Luna Caliente o Qué solos se quedan los muertos, también a Rubén Fonseca, y lo que quería era hacer una novela que tuviera ese tipo de giro.

El caso es que por esa época, en la época en que yo empecé a escribir esta novela, estamos hablando como de la primera mitad de los años 9o, tenía la impresión de que empezaban a aparecer escritores españoles que significaban una especie de renovación o de vanguardia, trunca después con el tiempo, pero que en ese momento tuvieron cierta fuerza. Eran Ray Loriga, José Ángel Mañas, una novela que se llama Raro, el Mañas de Historias del Kronen y de Mensaka, conformaron un pequeño momento de influencia. Entonces, esas ediciones en las que salía Loriga con su pelo largo y sus aretes de calaveras, unas cervezas y sus botas texanas y también [Juan Manuel de] Prada y Mañas, tenían estas referencias muy pop de los amigos que se iban de rumba y había como antologías de eso.

En Latinoamérica marcaron esta tendencia los de MacOndo, [Alberto] Fuguet, [Sergio] Gómez y cierta gente que se volcó a incorporar en la escritura una cosa muy pop, de amigos, de bailes y de bares. Entonces, por un lado me daba ánimo que existieran ese tipo de novelas, porque yo pensaba, no son tan buenos, o sea no eran malos, pero yo pensaba, si ellos están a ese nivel, yo podría llegar a ese nivel también. Me daba ánimo, porque, por un lado tenían cierta apertura temática, con cosas que pueden ser familiares a uno, a cualquiera. Por otro lado, aunque, por momentos, me parecían muy buenos, con ciertas cosas que funcionaban muy bien, me parecían fragmentarios. Tenían buenas páginas, pero no una historia, ahí fallaban. Héroes y La pistola de mi hermano de Ray Loriga son libros que tuvieron réplicas latinoamericanas en las que estaba ese [Rodrigo] Fresán primerizo y Fuguet con Mala onda y allá en Uruguay Gustavo Escanlar y Dany Umpi, narrando la noche, la rumba, la pastilla, la marihuana. A mí la impresión general que me daban esas novelas era que no construían una historia que fuera coherente, cerrada de principio a fin, que eran de trama desestructurada sí, pero amplia, en la que podían caber varios episodios dando una especie de instantánea vital de unos personajes medio perdidos, con cierto toque juvenil.

Yo sentía que había acumulado vida nocturna de bar como para contar sobre eso. Pero no quería que mi novela fuera una más de esas novelas con ese tipo de desestructura, no sentía que podía hacerlo bien, tenía cierta angustia de ponerme a escribir así, en pedazos. Pero igual me propuse hacer una novela de barrio, amigos y droga y todas esas influencias estaban ahí. También estaba la influencia de la novela Corazón Salvaje [Barry Gifford (1990)] luego llevada al cine por David Lynch y la película Asesinos por Naturaleza [Oliver Stone (1994)]; y todo ese tipo de novela que también venía como brit pop, fulián Tonelli de Diego 
Maté Jane y toda la literatura Pulp entre el comic y la narrativa, en Ediciones B. Ese tipo de narrativa quería hacer, pero que no tuviera una estructura abierta. Al mismo tiempo quería rendirle tributo al género policial, a lo que había leído y pensaba que podía escribir. Entonces, digamos que se juntaron, la historia de los amigotes con esas influencias y la novela negra clásica con las adaptaciones de ciertos referentes latinoamericanos.

El comienzo de la escritura supuso momentos de mucha exploración, de no saber de qué era capaz; cuando uno empieza a escribir tiene muchas inseguridades, después puede ganar pasos en los que se balancea la escritura y hay una cierta certeza sobre sus capacidades como escritor. Entonces, para escribirla lo que hice fue estrechar el camino para ir más lejos. Escogí un personaje que era de Cali, como yo, con una forma de narrar muy parecida a la oralidad, le adjudiqué un grupo de amigos los cuales yo podía tener como referentes, claro ficcionalizados, pero ciertos personajes con los que uno ha estado. Entonces hice una historia con personajes que conocía muy bien, con un estilo cercano al habla, a la forma más expedita de escribir, similar a cuando uno está chateando con un amigo y empleando un protagonista narrador en primera persona que podía compartir ciertas cosas conmigo. Es decir, no era un explorador en Alaska sino que vivía en un apartamento solo, como yo vivía, en una geografía que yo más o menos había recorrido y con ciertos referentes generacionales, de lecturas y de música, que podíamos compartir él y yo. Y esos elementos articulados en una historia, una sola, lineal, donde no se multiplican las voces. La hice muy a lo Bioy [Casares] cuando, según él, escribió La Invención de Morel. Él decía que básicamente la hizo tratando de no cometer errores y yo la escribí un poco así. Sentía el impulso de hacer un tipo de escritura de capítulos cortos a lo Luna Caliente, que uno la agarra y no la puede soltar, que va como en bajada. Y yo lo que hice fue escribir con la premisa de que no la fueran a soltar, encadenando un suceso con el otro y con un tiempo picado, acelerado.

Además de las influencias principales de género, estilo y estructura, la novela tiene guiños con autores y textos que me gustan, por ejemplo, cuando el personaje central busca la canción ideal para determinados momentos, eso es Vázquez Montalbán. Cuando el personaje de Vázquez Montalbán, que dejó la lectura como quien deja la heroína y tiene una inmensa biblioteca, va a quemar libros, o sea, no quiere volver a leer pero tiene los libros ahí y ¿qué hace? los despedaza, con ellos prende la chimenea, pero siempre antes lee un párrafo para ver si lo puede quemar o no. A veces dice que le da muchísimas ganas de leer cierto libro, por ejemplo de Bécquer, le da miedo volverse a enganchar con la lectura, y lo quema. Entonces le hago una especie de homenaje cuando mi personaje cita 
parte de una canción en el momento justo, escuchándola sonar. También uso ciertas referencias concretas como la cita de [William] Faulkner, algunas cosas de [William] Shakespeare, o la metáfora de Chandler que es traducción de Aira [César], ese tipo de guiños que están por ahí en la novela y que son guiños puntuales a ciertas lecturas. Ese es el sustrato de $S u$ Casa es mi casa.

Por otro lado, es también una especie de novela de iniciación, el tipo está en su primer apartamento solo y de alguna manera el empezar a vivir solo es como el primer paso a la adultez, hacerse cargo de sus cosas, como un coming to age. Se enfrenta por primera vez con la maldad del mundo, el aprender ciertas cosas, la pérdida de la inocencia, o sea, también es como una novela de formación.

Me parecía que trabajar el género [policial] implicaba incluir algún rasgo que fuera diferencial. Cuando uno trabaja con un género si uno es demasiado obediente entonces termina siendo una novela más del género, como de las docenas que puede haber ahí. Entonces pensé un par de cosas que podían funcionar innovadoramente, que tampoco me las inventé yo, pero que están en contravía de cierta normativa del género, por ejemplo, el personaje cobarde. Los personajes de novelas policiales casi siempre son duros, fuertes, toscos, que se dan de puños, en cambio este es un personaje que está todo el tiempo miedoso, queriendo huir. Sí, termina apretando el gatillo, pero es un personaje cobarde que todo el tiempo está asustado, que corretea muerto de susto, aunque no quiere estar así. Un personaje principal de novela policial con tanto miedo lo sitúa en el lugar del antihéroe, que además se ha trabajado caricaturescamente, como el detective Sledge Hammer, que es una especie de clown. Entonces, era como ir en contravía del estereotipo sin llegar al punto de romper la verosimilitud del personaje.

O.R.: No tiene clara la razón de por qué se mete en todo lo que se mete.

A.G.A.: Es como el territorio de la obsesión.

O.R.: Y al final termina cargando con toda una problemática social y política de corrupción.

A.G.A: De todo, porque la curiosidad mató al gato. $\mathrm{Y}$ hay un punto en el que se quiere salir, en un momento dice, ya, Ok. Pero llegó a un punto en el que cuando dice, este no es mi problema, ya era el problema de otras personas y cuando empieza a ser el problema de otras personas ya también es tu problema. Antes podías salir del problema si era solo tuyo. Pero cuando ya lo que sabes es el problema de otra gente, ya no es tu decisión salirte, ya es demasiado tarde. Ya su curiosidad empieza a tener consecuencias concretas.

O.R.: Son fuertes los párrafos donde él dice, nadie te va a agradecer que te estés jugando el pellejo por muertos que nadie llora, infidelidades que no dis- 
frutaste, negocios de los que no te dan parte, fotografías que no tomaste, ofensas que no te hicieron...

A.G.A.: Es el momento en que te das cuenta de que lo que estás haciendo es inútil pero ya no te puedes salir de eso y te invade la sensación de tiempo perdido inútilmente, una sensación incómoda de estupidez, de tiempo malgastado en maricadas. Ese es el momento en que el personaje está cuestionándose el haber llegado tan lejos, hasta ese punto en que los personajes van deslizándose sin querer y sin saber. También siento que es ese punto en el que ocurre cierto splint en la vida que te hace mirar a la vida de los demás para sentir que tu vida está completa, o al menos que no es tan mala. Mirar otras vidas de decadentes, de extorsionistas, de alguna manera hace que su vida tenga cierta validez, en la medida que es menos patética que la de ellos. Finalmente, su búsqueda hacia afuera es también una búsqueda hacia adentro. Su búsqueda tiene algo como de "el doble", del personaje que se siente como réplica de otro personaje. Él en algún momento lo dice, seríamos como una cadena, o sea, lo matan a él, me matan a mí por andar preguntando por él y de pronto viene uno más a sumarse a esta cadena de pendejos en busca de lo que pasó. Esta sensación de réplica, que él expresa en algún momento, en la que cada movimiento dentro del apartamento era una acción repetida del inquilino anterior, una copia de quien la había hecho antes, lo hace sentirse intruso dentro de su propia casa. Esta sensación está justificando su búsqueda, porque es como una especie de exorcismo, si se que le pasó, o si develo al fantasma, pues, ya estoy en mi casa.

O.R.: Entonces, este impulso por saber de la vida del otro, por un lado, lo deja más contento con su vida porque al menos, no lo raptan en camionetas rojas. Pero también es el puntapié de su proceso de apropiación de un lugar, Bogotá, que hasta entonces le era ajeno, peligroso, amenazante y ahí se articula la novela de iniciación, el paso a la adultez.

A.G.A: Se trata de encontrar un lugar en el mundo, ese lugar en el mundo que además de existencial es físico, pues es la casa, apropiarse de la casa. Yo me he dado cuenta que sistemáticamente tengo personajes muertos en casa. En Recursos humanos los personajes también se van a cambiar de casa, es algo que se repite. Además, la empresa se va expandiendo y va comprando las casas de alrededor, entonces los personajes abren una puerta y están en el living de una casa o en el cuarto. Es como que tengo esa recurrencia de personajes que se van a mudar o que se están mudando, o llegan a un lugar y tienen que apropiarse de ese sitio, habitarlo, desarraigarse de un sitio anterior, ese tipo de cosas.

O.R.: Esta búsqueda, que es a la vez exterior e interior, apunta también a apropiarse de la subjetividad. O sea, la posibilidad de habitar el lugar donde se 
vive pasa en la novela, por reconocerse en el doble, en ese otro ajeno y extraño pero, a la vez, familiar. Por ejemplo, cuando el personaje está escapando de que lo maten y se va con los amigos a Península [uno de los boliches de moda en Bogotá] dice: "El arrullo frenético de los sintetizadores es canción de cuna para nosotros, huérfanos de todas las utopías, sabiéndonos a priori, solitarios, empedernidos y promiscuos" (García, Su casa 29). Este es un momento de interpelación para el personaje, pero también para el lector, enfrentado a un espejo en el que quedan al descubierto sus miserias con las de toda una época. Y ocurre con cierta comicidad que le quita el tono de juicio, nos enfrenta a algo que nadie diría directamente con cierta liviandad cómica.

A.G.A: Es cierto que el personaje está metido en situaciones que pueden ser cómicas a pesar del miedo, el peligro o lo doloroso. El amigo hablando en español antiguo en Península, como efecto de la droga, momentos así como desopilantes, que se mezclan con momentos de autoconciencia del personaje. Esos momentos en que el personaje está pensándose a sí mismo son los que impiden que la novela se vaya al territorio de la comedia, o al de la novela negra también, que es una novela, a veces con menos interioridad de los personajes. Incluso, por ejemplo, en Luna Caliente que al tipo le da una especie de calentura extrañísima y termina teniendo sexo con la niña de trece años, pero después el personaje sigue siendo inexplorado en su interior, no hay un momento de pasado, ni de historia familiar. Es un personaje mucho más iceberg que el mío que tiene más interioridad, más historia. Y ahí también está como ese esplín que estaban explorando ciertos autores generacionales: un personaje de veinte y pocos años, con ciertas inquietudes, ciertas interrogantes sobre su vida y su lugar en el mundo, supongo que también ese es un momento de apelación emocional con el lector o algo así. Igual cuando el personaje siente que se va a morir y siente que se puede ir dejando tantas cosas por hacer y dice que nunca vio estrellas fugaces, que tiene un poco de amigos y ni siquiera tales y un par de medallas de natación, que no conoció el amor ni extrañó a alguien de manera definitiva, que no lloró cuando debió hacerlo, ni pidió perdón. Es un momento en el que está haciendo un balance vital, pensando, ¿ me voy a morir ya?, con cierta sensación de que te vas a morir incompleto.

O.R.: Con una vida vivida a medias... dice textualmente, "y te da rabia saber que si te morías, te morís arrepentido, que ni siquiera eso hiciste bien del todo; que fuiste víctima de vos mismo, fuiste tu peor enemigo" (García, Su casa 125)

A.G.A.: Eso, esa sensación es también la que yo creo que hace que el personaje tenga cierto instinto de supervivencia que, en algún momento, se parece al heroísmo. 
O.R.: Ya que tocaste ese tema, al final el único que le agradece al personaje central lo que hizo es Jairo. Después de estar ocultándose en el bar El Polo durante meses, cuando puede volver a su pueblo a rehacer su vida, es el único que le dice gracias. Ahí hay algo también fuerte, porque Jairo es un personaje marginal, chofer, servidumbre de la actriz acomodada. Martín termina, sin proponérselo, arriesgando su vida para lograr que este hombre deje de vivir en la clandestinidad, amenazado de muerte por los matones de Torrado.

A.G.A.: Sí, yo creo mucho en la victoria pírrica. Es decir, yo a mis personajes o los derroto o les doy una victoria pírrica, como la del general romano, Pirro de Lerna. Pirro salía con mil soldados a luchar una guerra y volvían tres, uno sin pierna, otro gravemente herido y ciego y él más o menos, pero ganaba la guerra. Nunca perdió una batalla, aunque las batallas que ganaba siempre eran a costa de muchísima sangre, quedando con vida solo un puñado de hombres. Eran enfrentamientos tan trabajosos que a veces les iba mejor, incluso, a los que tenían una derrota. De ahí sale la victoria pírrica, a la larga los malos están muertos, pero los buenos terminan en un hospital todos quebrados y maltrechos y tu novia o lo que pensabas que era el amor, esa mujer ya tampoco sigue ahí.

O.R.: Una última pregunta que va más hacia la parte social o histórica. Me llamó mucho la atención que no se nombra, en la novela, el narcotráfico. Se puede intuir que el policía y el político corruptos además de estar involucrados en desfalcos, chantajes y prostitución, están también en el narcotráfico, más cuando mencionas la fachadas de mármol y las columnas griegas de la mansión donde llevan a Martín para torturarlo y matarlo, características de la narcocultura. Sin embargo, no mencionas el narcotráfico, ¿evitas la narcoliteratura? ¿cómo lo pensaste?

A.G.A.: Lo que pasa es que yo creo que ese género es un género colombiano si se quiere. La sola mención del tema te obliga a meterte en un asunto que si lo tratas, quizá no se, pero quizá si lo nombras, estás comprometiéndote con ciertos desarrollos en lo social y en lo sociológico que de no hacerlos quedarías como frívolo, haciendo un libro que se sirve de eso con cierta frivolidad, digamos. Además, yo pienso que hay cierto grado de elaboración que viene más de la lectura que de la observación en este caso, pues son unos malos más literarios que tomados de modelos de afuera. Incluso si vamos a las categorías de Edward Morgan Forster, de personajes redondos y personajes planos, obviamente entre los planos están casi todos los mafiosos de mi novela. Sin embargo, por ejemplo, ella, la Sanders, es un personaje redondo que tiene una interioridad, un conflicto y se cuenta su historia. En cambio los mafiosos son personajes caracterizados desde afuera, con la cicatriz, el apodo y yo creo que en esa medida yo no tomé un refe- 
rente extraliterario. Ahí estoy en el territorio que se construye desde los libros, desde la literatura y que es un procedimiento que hizo Borges y que hizo Bioy y en gran medida la literatura se ha hecho desde ese costado. Pero, para hacer eso tienes que tener otros referentes para compensar ese grado de no raigambre en la realidad, entonces los lugares de la ciudad tienen que estar bien documentados. Si ellos pasan por la 16, ahí está este sitio y el otro y la oscuridad, y este lugar tiene esto y lo otro, porque entonces, si balanceas puedes poner a un personaje salido de la literatura en lugares específicos de la realidad y lograr un buen ensamble y no va a parecer que el personaje es una extracción burlesca.

O.R.: Sin embargo, aunque no trabajas desde los sociológico, hay en la novela momentos muy interesantes de choques o más bien de encuentros de clases, como cuando estos estudiantes de universidades privadas van al barrio de Jairo a pedirle refugio, se esconden en El Polo y duermen en un hotel de cuarta.

A.G.A.: Sí, hay cierta cosa medio lumpenesca si se quiere. De alguna manera ellos están ahí como desclasándose, porque son estudiantes de las universidades más caras de Bogotá y en un momento ellos lo dicen, somos niños consentidos de safari por los bajos fondos. Yo creo que ese descenso también tiene el toque de la novela de iniciación, del relato juvenil. Pero lo que hace Jack London es mandarlos para la selva. Yo los mando para la 16, que duerman allá, en un cuarto de 30 mil pesos y terminen asociándose con el chofer de la Sanders para sobrevivir; y hasta encontrándose con ese personaje de Ráquira, que es una especie de vividor que anda en chanclas y que no es muy estudiado, sino que es como los personajes vulgares y simples que aparecen en la novela. Al mismo tiempo, aunque esos extremos estén muy separados, por momentos se tocan y eso es muy colombiano también. $\mathrm{O}$ sea, estas intersecciones que desafían cierta conformación social clasista, que es tal cual como las sociedades latinoamericanas, muy patricias.

O.R.: Elitistas, sí y eso se ve en la novela también del otro lado, cuando no los dejan entrar a Península porque vienen con Jairo.

A.G.A.: Sí. En estos tránsitos que van de arriba hacia abajo y de abajo hacia arriba, todos tienen dificultad para entrar en el mundo del otro, aunque compartan el alcohol y las peleas. Pero los amigos de Martín insisten porque quieren irse con él de rumba y lo sacan desde los bajos fondos hasta un boliche exclusivo.

O.R.: Y cuando Jairo logra entrar se siente incómodo, fuera de ambiente y ahí es que dice: "Me voy a dar cuenta que soy pobre, morenito y mal vestido, me voy a meter en un rincón a mirar a esa parranda de niños bonitos que se creen que cagan masmelo y mean Lapidus [...] y me voy a deprimir" (García, Su casa 109). 
Bueno ya estamos en la última parte de la entrevista, donde te voy a leer algunas afirmaciones y vos me decís lo que se te ocurra, al estilo libre asociación. Las afirmaciones no están relacionadas con la novela, es más como el escritor pensando otras cosas. La primera tiene que ver con la subjetividad colombiana: "los colombianos no tocamos fondo lo construimos".

A.G.A.: Yo creo que los colombianos, o en todas las sociedades, el fondo siempre está lejos. Siempre están los síntomas del descenso, pero construir el fondo es como ponerle fondo a ciertas tendencias locales o colombianas o nacionales, que es muy difícil. Además las cosas siempre pueden empeorar en cualquier momento. No creo que seamos capaces de construir un fondo, por lo menos si construimos fondo es temporal, siempre podemos sacarle otro sótano todavía.

O.R.: "A los colombianos nos salva lo mismo que nos condena".

A.G.A.: Eso lo dice muy bien García Márquez en esta proclama que se llama "Por un país al alcance de los niños". Dice que por los mismos motivos podemos ser tan constructivos como destructivos y entonces da una enumeración maravillosa. Quien responde esa pregunta de la mejor manera es Gabo. "Esta encrucijada de destinos ha forjado una patria densa e indescifrable donde lo inverosímil es la única medida de la realidad. Nuestra insignia es la desmesura. En todo: en lo bueno y en lo malo, en el amor y en el odio, en el júbilo de un triunfo y en la amargura de una derrota. Destruimos a los ídolos con la misma pasión con que los creamos. Somos intuitivos, autodidactas espontáneos y rápidos y trabajadores encarnizados, pero nos enloquece la sola idea del dinero fácil. Tenemos en el mismo corazón la misma cantidad de rencor político y de olvido histórico. Un éxito resonante o una derrota deportiva pueden costarnos tantos muertos como un desastre aéreo. Por la misma causa somos una sociedad sentimental en la que prima el gesto sobre la reflexión, el ímpetu sobre la razón, el calor humano sobre la desconfianza. Tenemos un amor casi irracional por la vida, pero nos matamos unos a otros por las ansias de vivir. $\mathrm{Al}$ autor de los crímenes más terribles lo pierde una debilidad sentimental. De otro modo: al colombiano sin corazón lo pierde el corazón. Pues somos dos países a la vez, uno en el papel y otro en la realidad. Aunque somos precursores de las ciencias en América, seguimos viendo a los científicos en su estado medieval de brujos herméticos, cuando ya quedan muy pocas cosas en la vida diaria que no sean un milagro de la ciencia. En cada uno de nosotros cohabitan, de la manera más arbitraria, la justicia y la impunidad; somos fanáticos del legalismo, pero llevamos bien despierto en el alma un leguleyo de mano maestra para burlar las leyes sin violarlas, o para violarlas sin castigo. Amamos a los perros, tapizamos de rosas el 
mundo, morimos de amor por la patria, pero ignoramos la desaparición de seis especies animales cada hora del día y de la noche por la devastación criminal de los bosques tropicales y nosotros hemos destruido sin remedio uno de los grandes ríos del planeta. Nos indigna la mala imagen del país en el exterior, pero no nos atrevemos a admitir que la realidad es peor. Somos capaces de los actos más nobles y de los más abyectos, de poemas sublimes y de asesinatos dementes, de funerales jubilosos y parrandas mortales. No porque unos seamos buenos y otros malos, sino porque todos participamos de ambos extremos. Llegado el caso -y Dios nos libre- todos somos capaces de todo" (García Márquez 15). Es eso y lo comparto. Esos párrafos de García Márquez son los que dan la medida exacta de las cosas en este país.

O.R.: Esto me hace recordar otra cita de la novela, cuando el personaje dice: "En el fondo los dos entendimos que el mundo no siempre se dividía en valientes y cobardes, sino en armados y desarmados" (138).

A.G.A.: Solo tienes que tener el arma, no ser bueno o malo.

O.R.: "En Colombia los políticos corrompen a los narcotraficantes"

A.G.A.: Esa es buena, ¿no? Es una exageración que nos retrata. Casi que se parecen a la literatura fantástica las cosas que pasan acá. Pero también es muy latinoamericano, cuando uno lee esos libros como El País de las maravillas o Diatriba por la Patria, que son una especie de alegatos sobre el país, piensa, claro, somos muy parecidos.

O.R.: ¿Con quién compartís el arte de escribir en Colombia, cuáles son tus pares a la hora de escribir?

A.G.A.: Reconozco algunos autores más grandes que yo, digamos, que construyen una obra que a mi me parece que me habla y que admiro y que siento que han dado claves para la escritura en Colombia. Por ejemplo, Tomás González, que es buenísimo. Y hay algunos libros que ya están dentro del canon, que siento que me dicen ciertas cosas, como Los Ejércitos de Evelio Rosero. De la generación que es un poco mayor que la mía, que están como pisando los 50, que son Mario Mendoza, Santiago Gamboa, reconozco algunos textos de ellos que me parece que están bien y que me gustan, como Los Impostores de Santiago Gamboa o El olvido que seremos de Héctor Abad. Y tengo amistad, y también muchas coincidencias literarias y personales con Pilar Quintana, que es caleña y que ha tocado el tema de Cali y que nos reconocemos como pares en ciertas búsquedas literarias o estilísticas. Y amigos, pues del oficio porque como somos tan poquitos terminamos conociéndonos: Ángel Burgos, Ricardo Silva, Margarita Posada, escritores que son pares de uno, que van en el mismo camino, abriendo la brecha con uno. 


\section{Obras citadas}

García Ángel, Antonio. Su casa es mi casa. Bogotá: Editorial Norma S.A., 2008.

García Márquez, Gabriel. "Por un país al alcance de los niños". Tres cuentos y una proclama. Edición número 100. Libro al Viento. Bogotá: Alcaldía Mayor de Bogotá y Idartes (Instituto Distrital de las Artes), 2014 • 4-7. 